\title{
BMJ Open Associations of occupational stress with job burn-out, depression and hypertension in coal miners of Xinjiang, China: a cross-sectional study
}

\author{
Xianting Yong (D) , Xiaoyan Gao, Zhe Zhang, Hua Ge, Xuemei Sun, Xiaofan Ma,
} Jiwen Liu

\begin{abstract}
To cite: Yong X, Gao X, Zhang Z, et al. Associations of occupational stress with job burn-out, depression and hypertension in coal miners of Xinjiang, China: a crosssectional study. BMJ Open 2020;10:e036087. doi:10.1136/ bmjopen-2019-036087

- Prepublication history and additional material for this paper are available online. To view these files, please visit the journal online (http://dx.doi. org/10.1136/bmjopen-2019036087).
\end{abstract}

Received 29 November 2019 Revised 10 June 2020 Accepted 16 June 2020

Check for updates

(C) Author(s) (or their employer(s)) 2020. Re-use permitted under CC BY-NC. No commercial re-use. See rights and permissions. Published by BMJ.

Department of Occupational Health and Environmental Health, College of Public Health, Xinjiang Medical University, Urumqi, Xinjiang, China

Correspondence to

Dr Jiwen Liu;

liujiwendr@sina.com

\section{ABSTRACT}

Objective Strategies and measures for fighting occupational stress in China are inadequate. This study aimed to determine the level of occupational stress in coal miners and to assess the associations between occupational stress and job burn-out, depression and hypertension. The results could provide clues for preventive measures and strategies to improve the psychological well-being of this population.

Design Cross-sectional study.

Setting Xinjiang Coal Administration Bureau.

Participants Four coal mines were selected randomly (computer-generated random number-based selection process) from the 21 coal mines of Xinjiang, and all miners with $>1$ year of employment were screened for participation.

Primary and secondary outcome measures A general demographic questionnaire, the Self-rating Depression Scale, the Effort-Reward Imbalance (ERI) model and the Maslach Burn-out Inventory.

Results A total of 1400 questionnaires were collected, including 1334 (95.3\%) valid questionnaires. This survey indicated that 1107 (83.0\%) participants with an ERI score $>1$ (high occupational stress) and 227 (12.8\%) had ERI $\leq 1$. Severe depression was found in $21.7 \%$ of the participants. Job burn-out was positively correlated with occupational stress, which was, in turn, associated with depression. Multivariable linear regression analysis showed that depression ( $\beta=0.006, p=0.012)$, sex $(\beta=0.358, p<0.001)$ and occupational stress $(\beta=0.702, p<0.001)$ were independently associated with job burn-out. Working years $(\beta=-0.086, p=0.015)$ and job burn-out $(\beta=0.022$, $p<0.001$ ) were directly associated with depression. Conclusion This study highlights that occupational stress may affect job burn-out, depression symptoms and hypertension. A higher degree of occupational stress was associated with poorer mental status and hypertension.

\section{INTRODUCTION}

There is a high demand for workers given the recent economic development and technological progress in China, and workers increasingly feel pressure. ${ }^{1}$ Occupational stress refers to job demands beyond one's working resources, abilities and needs, and
Strengths and limitations of this study

Even though it was a cross-sectional study, a randomised sampling method was used.

- The study population is homogeneous, and the sample size is large.

- Valid and reliable questionnaires (validated in Chinese) were used, decreasing the bias.

- The cross-sectional design prevented the determination of causal relationships.

- Social support and organisation and family backgrounds were not assessed. Not all job types related to coal mining were examined.

when employees are exposed to harmful physical and emotional environments. It is commonly experienced in response to several adverse conditions related to the working environment and has attracted increasing attention in the recent years. ${ }^{2}$ The mental and hypertension outcomes of workers are affected by extended periods of work pressure caused by occupational stress through non-specific pathways, ${ }^{3}$ including the cardiovascular, central nervous system and immune system diseases. Other effects include reduced concentration, decreased working efficacy and sleep disturbances. ${ }^{4} 5$ More importantly, some coal mining accidents are caused by occupational stress. ${ }^{6}$ According to the American Institute of Stress, occupational stress is responsible for $80 \%$ of all work-related injuries and $40 \%$ of workplace errors, while $30 \%$ of European staff and workers experience the effects of work-related stress. ${ }^{7}$ A systematic review demonstrated that $22 \%$ of workers with highrisk responsibilities experience occupational stress. ${ }^{7}$ Stress is a significant part of the living conditions of coal miners, correlating with harsh working conditions, including repetitive activities, lifting heavy materials, shift 
work and night work. ${ }^{8}$ Besides, job burn-out results from working stress, and inappropriate work environment can trigger depression. ${ }^{9}$ In addition, a study revealed average rates of $18.6 \%, 26.4 \%$ and $23.5 \%$ for hypertension, hyperlipidaemia and hyperglycaemic, respectively, in coal miners. ${ }^{10}$ Therefore, hypertension should be evaluated in relation to working conditions.

Between 2010 and 2014, there were almost 4.7 million coal miners in China. ${ }^{6}$ Xinjiang is one of the main coal deposits and is employing a large number of coal miners. Coal miners involved in underground work have a degree of mental burden score of 8.3, representing one of the heaviest mental burdens among 150 occupations. ${ }^{11}$ Due to the high labour intensity and a dangerous working environment, coal miners are at risk of mental diseases, and limited working hours and hard labour also increase occupational stress in this population. ${ }^{12}{ }^{13} \mathrm{~A}$ report revealed that some coal miners become agitated due to chronobiological disorders caused by shift working and repetitive ancillary activities such as changing clothes and getting lamps. ${ }^{14}$ Moreover, an online survey of coal miners revealed that mental health problems induced by mental stress should not be neglected. ${ }^{15}$

Occupational health research in China remains limited, and strategies and measures for combating occupational stress are inadequate. In China, the focus is placed on lung diseases in coal miners, neglecting mental health. ${ }^{16}$ Internationally, only a few studies have investigated occupational stress and mental health due to strict legislation of coal mine safety. It was found that organisational policy and training quality are the main sources of mental pressure. ${ }^{17}$ Meshi et al demonstrated that factors aggravating occupational stress in coal miners include the imbalance between payout and return, as well as irregular working schedule and shift working. ${ }^{14}$

Therefore, the levels of occupational stress, job burn-out, depression and hypertension in coal miners, as well as the relationships among them, are poorly known. China's coal accounts for about $13.9 \%$ of the world's total amounts, and Xinjiang is one of the main sources of Chinese coal. ${ }^{16}$ Coal miners' health is closely associated with the rapid development of the national economy. Coal miners represent a special group of workers. They work for a long time in the dark, damp underground, under a high degree of danger, which is conducive to suffer from occupational stress. There is little research on the physical and mental health of coal miners in China and around the globe. Most available research focused on lung disease, but less on other diseases, especially mental health. In order to provide preventive strategies and evidence for improving the mental status and hypertension in coal miners, this study aimed to determine the level of occupational stress in coal miners and to assess the associations between occupational stress and job burn-out, depression and hypertension.

\section{METHODS}

\section{Participants}

This cross-sectional study was carried out between March and December 2018. The target population included all coal miners of the Xinjiang Coal Administration Bureau. There are 21 coal mines and almost 200000 employees performing work related to the coal industry in Xinjiang Province. Four coal mines were selected randomly (computer-generated random number-based selection process) from the 21 coal mines of Xinjiang. The four mines included a large coal company (annual production $>120 \mathrm{t}$ ) and a small coal company (annual production $<30 \mathrm{t})$ in northern Xinjiang, and a large coal company (annual production $>120 \mathrm{t}$ ) and a small coal company (annual production <30t) in southern Xinjiang. All workers were screened for participation. The inclusion criteria were: (1) between 18 and 60 years of age and (2) $>1$ year of employment. Participants with a diagnosis of mental disorder were excluded. All participants provided written informed consent.

\section{Patient and public involvement}

No patients involved.

\section{Measurement parameters}

The field questionnaire survey method was adopted. After the physical examination of coal miners, a centralised questionnaire survey was conducted, and the questionnaire forms were collected on the spot. The questionnaire consisted of four parts, including basic information, the Effort-Reward Imbalance (ERI) questionnaire, the SelfRating Depression Scale (SDS). This survey used a selffilling questionnaire. Since the education level of coal miners is relatively low, in order to ensure the accuracy of the questionnaire, the filling methods and standards are described at the top of the questionnaire. The quality of the filled questionnaire was checked by the investigators, supplementing missing items.

The general demographic characteristics included sex, age, working age, educational background, type of work, marital status, income, and smoking and drinking statuses. The participants were asked to answer 'yes' or 'no' to a drinking statuses regarding whether they drink(self-reported ) .

\section{Effort-Reward Imbalance}

To assess occupational stress, the Chinese version of the ERI questionnaire ${ }^{18}$ was completed by the participants. This questionnaire theoretically detects whether the individual's work effort is equal to the reward. It contains three modules consisting of 23 items in total, including working effort (6 items), working reward (11 items) and working engagement (6 items). Participants responded to every item on a five-point scale ranging from 1 (never) to 5 (always). A total score was calculated for each participant. A tense state referred to high effort and low reward according to the ERI scale, while low effort and high reward indicated no occupational stress. In terms 
of score, ERI $>1$ indicated high effort and low reward, ERI $=1$ suggested balanced effort and reward, and ERI $<1$ indicated high reward and low effort. The higher the ERI score, the higher the level of occupational stress. In addition, a higher working effort score indicates a heavier working load. ${ }^{19}$

\section{Job burn-out}

The Maslach Burn-out Inventory (MBI) questionnaire was used to assess job burn-out symptoms. It contains three parameters, including emotional exhaustion, depersonalisation and reduced accomplishment. ${ }^{20}$ Emotional exhaustion refers to physical and emotional depletion caused by weary and worn-out states, including fatigue, exhaustion and worries, brought by work to the emotional state. Depersonalisation reflects a poor social relationship and an indifferent, negative attitude to work. Reduced accomplishment indicates that an individual has a negative self-assessment of work accomplishment,that is, a sense of incompetence and a lack of work achievement or working efficiency. Each parameter consists of five items, for a total of 15 items. MBI has high reliability and validity. Three critical values ${ }^{11} 1621$ delineate four levels of job burn-out, namely, no burn-out (scores below the respective critical values ${ }^{11}{ }^{21}$ in all three parameters), mild burn-out (scores no lower than the respective critical values in any parameter); moderate burn-out (scores no lower than the respective critical values in any two given parameters) and severe burn-out (scores no lower than the respective critical values in all three parameters).

\section{Depression}

The SDS compiled by Sirodff in 1977 was used to evaluate depression symptoms. ${ }^{22}$ The scale has 20 items, with the three-rank estimate system applied based on the frequency of symptoms or feelings over the past week. More specifically, 0 refers to no symptoms, 1 to seldom symptoms, 2 to frequent symptoms and 3 to permanent symptoms. The critical value for the SDS is a score of 16 . Thus, participants with scores $>16$ were considered to be experiencing depression symptoms. More importantly, four levels of depression were determined: no $(<16)$, mild $(16-19)$, moderate $(20-23)$ and severe $(\geq 24){ }^{23}$

\section{Physical health examination}

Following occupational health regulations, 508 of the current subjects had health examination by the Xinjiang Occupational Health Examination Organisation, assessing parameters such as body mass index (BMI) and blood pressure.

Hypertension was screened during the mandatory routine physical examinations. Blood pressure was measured as follows. After the medical staff calibrated the arm-type electronic blood pressure metre, the examinee sat straight with the elbow and heart at the same level. Blood pressure in the right arm was measured twice and averaged. In case of a difference exceeding $5 \mathrm{~mm} \mathrm{Hg}$ between the two values, the examinee had to rest for
5 min before a retest, and the final blood pressure was the average value of the three measurements. After the first examination, the workers suspected of hypertension were followed twice within 3 weeks after the first physical examination. Diagnostic criteria for hypertension were: systolic blood pressure $\geq 140 \mathrm{~mm} \mathrm{Hg}$ and/or diastolic blood pressure $\geq 90 \mathrm{~mm} \mathrm{Hg}$. ${ }^{24}$

According to the 2007 edition of the guidelines for prevention and control of overweight and obesity in Chinese adults ${ }^{25}$ standard and calculation method: BMI $\left(\mathrm{kg} / \mathrm{m}^{2}\right)=$ weight $(\mathrm{kg}) /$ height $^{2}\left(\mathrm{~m}^{2}\right)$. BMI $<18.5 \mathrm{~kg} / \mathrm{m}^{2}$ is underweight, BMI $18.5-23.9 \mathrm{~kg} / \mathrm{m}^{2}$ is normal, BMI 24.0 $27.9 \mathrm{~kg} / \mathrm{m}^{2}$ is overweight and $\mathrm{BMI} \geq 28 \mathrm{~kg} / \mathrm{m}^{2}$ is obese.

\section{Quality control}

All study procedures adhered to Good Clinical Practices. Before the formal survey, occupational and mental health researchers revised the questionnaires. Before the formal investigation, 50 first-line coal miners from Shenhua coal mine in Xinjiang were selected for a preliminary investigation to test the questionnaires. All data were double entered, and any discrepancy in the database comparison was corrected based on the original paper documents.

\section{Statistical analysis}

All data were collected with Epidata V.3.1, and statistical analyses were performed with SPSS V.17.0 (IBM). Continuous variables were presented as means $\pm \mathrm{SD}$, and group pairs were compared by the Student t-test. Categorical data were expressed as $\mathrm{n}(\%)$, and the $\mathrm{X}^{2}$ test or Fisher's exact test was used for comparison. Correlations were tested using the Pearson or Spearman correlation analysis. Multivariable analysis was performed by multiple linear regression. The significance level was $\mathrm{p}<0.05$.

\section{RESULTS}

\section{Participant characteristics}

A total of 1400 questionnaires were distributed, and 1344 were returned, for a recovery rate of $95.3 \%$. The participants were $42.2 \pm 8.6$ years old, with a median of 31.5 (1, 42) working years. The demographic characteristics are shown in table 1 . No participants were excluded due to a mental disease.

The patients were divided into two groups based on occupational stress levels, and there were 1107 (83.0\%) participants with an ERI score $>1$, and $227(12.8 \%)$ had ERI $\leq 1$ (there were $56(4.2 \%)$ participants with ERI=1). As shown in table 1 , there were statistically significant differences between the two groups in sex, age, working years, level of education and annual income $\left(\mathrm{X}^{2}\right.$ test, all $\mathrm{p}<0.05)$. These findings indicate that longer working years, higher educational level, marriage, lower annual income, and male sex were associated with occupational stress. 
Table 1 Demograhpic characteristics of the included coal miners by occupational stress level indicated with Effort-Reward Imbalance (ERI) score $(n=1334)$

\begin{tabular}{|c|c|c|c|c|}
\hline & $\begin{array}{l}\text { Total } \\
(n=1334)\end{array}$ & $\begin{array}{l}\text { ERI >1 } \\
(n=1107)\end{array}$ & $\begin{array}{l}\text { ERI } \leq 1 \\
(n=227)\end{array}$ & $P$ value \\
\hline Sex, n (\%) & & & & $<0.001$ \\
\hline Male & $1173(87.9)$ & $1040(88.6)$ & $133(11.4)$ & \\
\hline Female & $161(12.1)$ & 67 (41.6) & $94(58.4)$ & \\
\hline Age, n (\%) & & & & 0.024 \\
\hline$\leq 30$ & $202(15.1)$ & $158(78.2)$ & $44(21.8)$ & \\
\hline $31-45$ & $575(43.1)$ & $470(81.7)$ & $105(18.3)$ & \\
\hline$>45$ & $557(41.8)$ & $479(86.0)$ & $78(14.0)$ & \\
\hline Working years, n (\%) & & & & $<0.001$ \\
\hline$\leq 15$ & $623(46.7)$ & $488(78.3)$ & $135(21.7)$ & \\
\hline$>15$ & $711(53.3)$ & $619(87.1)$ & $92(12.9)$ & \\
\hline Work type, n (\%) & & & & 0.073 \\
\hline Coal digger & 266 (19.9) & $222(83.5)$ & $44(16.5)$ & \\
\hline Driver & $72(5.4)$ & $55(76.4)$ & 17 (23.6) & \\
\hline Electrical fitter & $274(20.5)$ & $235(85.8)$ & $39(14.2)$ & \\
\hline Hauler & $94(7.0)$ & $74(78.7)$ & $20(21.3)$ & \\
\hline Safety worker & $211(15.8)$ & $165(78.2)$ & $46(21.8)$ & \\
\hline Ground & 417 (31.3) & $356(85.4)$ & $61(14.6)$ & \\
\hline Working shift, n (\%) & & & & 0.900 \\
\hline Fixed the day & $476(35.7)$ & $398(83.6)$ & $78(16.4)$ & \\
\hline Work on two shifts & 203 (15.2) & $168(82.8)$ & $35(17.2)$ & \\
\hline Three shifts & $655(49.1)$ & $541(82.6)$ & $114(17.4)$ & \\
\hline Level of education, $\mathrm{n}(\%)$ & & & & $<0.001$ \\
\hline Middle school or below & $671(50.3)$ & $486(72.4)$ & $185(27.6)$ & \\
\hline Middle school above & $663(49.7)$ & $621(93.7)$ & $42(6.3)$ & \\
\hline Marital status, n (\%) & & & & 0.143 \\
\hline Spinsterhood & $138(10.3)$ & $107(77.5)$ & $31(22.5)$ & \\
\hline First marriage & $1153(86.4)$ & $966(83.8)$ & $187(16.2)$ & \\
\hline Other & $43(3.2)$ & $34(79.1)$ & $9(20.9)$ & \\
\hline Annual income, $n(\%)$ & & & & 0.003 \\
\hline$\leq 60000$ & $1116(83.7)$ & 941 (84.3) & $175(15.7)$ & \\
\hline$>60000$ & 218 (16.3) & $166(76.1)$ & $52(23.9)$ & \\
\hline Smoking, n (\%) & 725 (54.3) & $602(83.0)$ & $123(17.0)$ & 0.957 \\
\hline Drinking, n (\%) & $783(58.8)$ & $650(83.0)$ & $133(17.0)$ & 0.972 \\
\hline
\end{tabular}

Underground work professionals included coal diggers, drivers, electrical fitters, haulers and safety workers. Other marital statuses included remarriage, divorce and widowed.

$P<0.05$

\section{Mental health and hypertension in coal miners}

In this study, there were $631(47.3 \%), 397(29.8 \%)$, $180(13.5 \%)$ and $126(9.4 \%)$ coal miners with no, mild, moderate and severe burn-out levels, respectively (table 2). All participants with job burn-out of mild and moderate level had ERI $>1$. The ERI score of participants with severe job burn-out in the ERI $\leq 1$ group were all equal 1. In other words, all participants with ERI $<1$ had no job burn-out. Therefore, there were significant differences in job burn-out levels between coal miners with ERI $>1$ and ERI $<1 \quad(\mathrm{p}<0.001)$, indicating that coal miners with occupational stress had a higher job burn-out level (table 2).

The depression status of coal miners was divided into four levels (no, mild, moderate and severe). As shown in table 2, 82.2\% (mild), $91.7 \%$ (moderate) and $83.0 \%$ (severe) coal miners with depression were in the ERI $>1$ group. These data indicated significant differences in depression between the ERI $>1$ and ERI $<1$ groups 
Table 2 Occupational stress level indicated by Effort-Reward Imbalance (ERI) score in relation to depression, job burn-out and hypertension

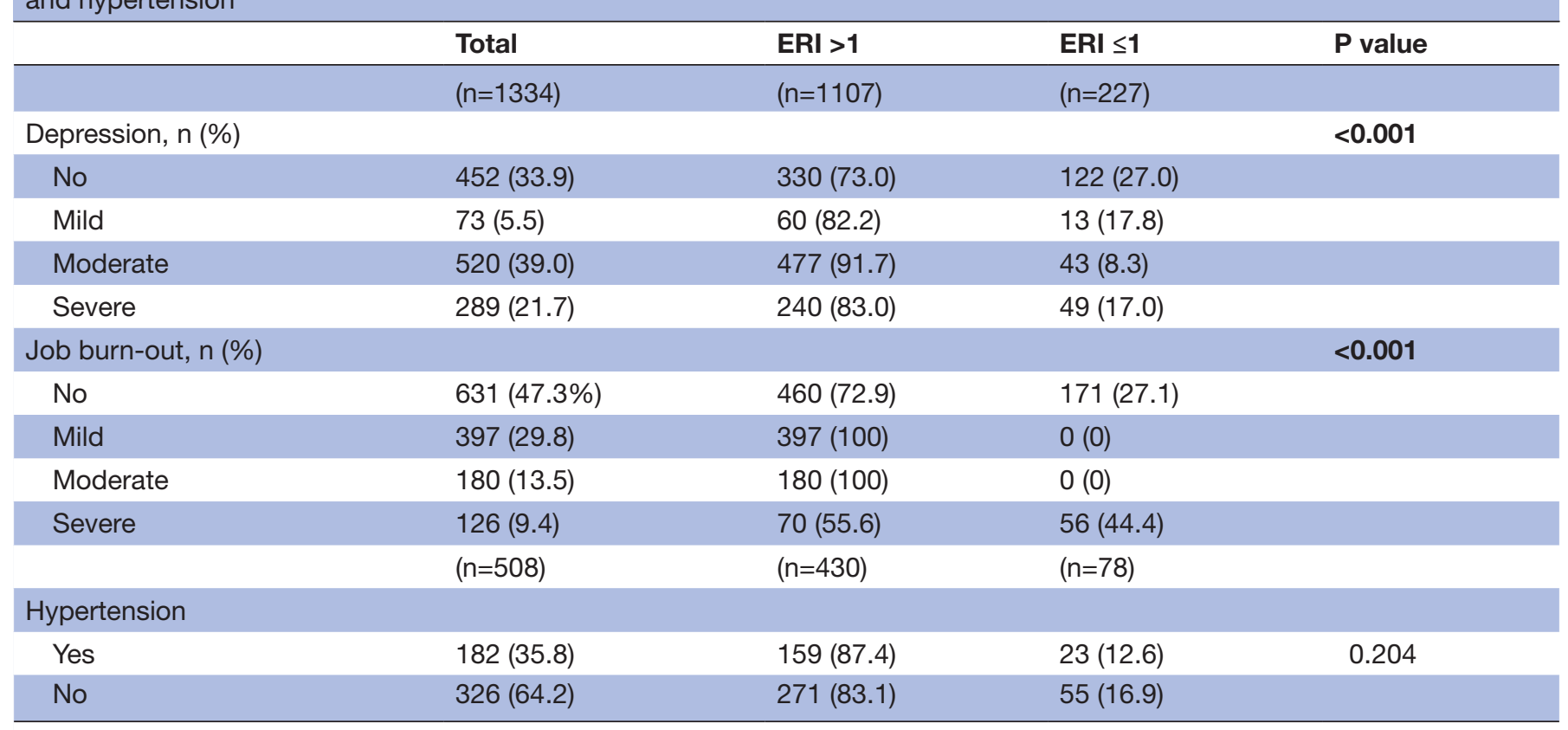

$P<0.05$

$(\mathrm{p}<0.001)$, indicating that coal miners with occupational stress had a higher depression level (table 2). There were $182(35.8 \%)$ participants with hypertension. There was no significant difference between the ERI $>1$ and ERI $\leq 1$ groups in hypertension prevalence (table 2).

Risk factors for job burn-out and depression in coal miners In the multivariable linear regression model, job burn-out and depression score of coal miners were entered as the dependent variable, and other parameters as independent variables, including sex, age, working years, educational level, work type, marital status, work shift, annual income and ERI and depression scores. The analysis indicated that the ERI score $(\beta=0.702, \mathrm{SE}=0.04 ; \mathrm{p}<0.001)$, $\operatorname{sex}(\beta=0.358, \mathrm{SE}=0.077 ; \mathrm{p}<0.001)$ and depression score $(\beta=0.006, \mathrm{SE}=0.002 ; \mathrm{p}=0.012)$ were independently associated with job burn-out. These data indicated that male coal miners with high ERI score and depression scores had a greater risk of job burn-out. Two factors directly contributed to depression, including job burn-out score $(\beta=0.022, \mathrm{SE}=0.002 ; \mathrm{p}<0.001)$ and working years $(\beta=-0.086, \mathrm{SE}=0.035 ; \mathrm{p}=0.015) \quad($ table 3$)$.

\section{Risk factors for hypertension}

Before logistic regression analysis, a $\mathrm{X}^{2}$ test was performed with possible relevant variables (online supplementary table S1). In this analysis age, working type, working shift, degree of education, marital status, annual income, smoking status, drinking status, BMI, ERI, job burn-out and depression. In this analysis, age, working type, working shift, drinking status, BMI, ERI and depression showed statistical significance and were included in the multivariable analysis (online supplementary table S1).
The logistic regression model revealed that drinking (OR 2.55, 95\% CI 1.30 to 5.0; $\mathrm{p}=0.006$ ), ERI $>1$ (OR $3.03,95 \%$ CI 1.67 to $5.52 ; \mathrm{p}<0.001$ ), age $>45$ (OR 8.39 , $95 \%$ CI 3.53 to 19.95 ; $<<0.001$ ), work on two shifts (OR $0.32,95 \%$ CI 0.15 to $0.69 ; \mathrm{p}=0.004$ ), overweight (OR 0.27 , $95 \%$ CI 0.14 to $0.53 ; \mathrm{p}<0.001$ ), mild depression (OR 4.10, $95 \%$ CI 1.96 to $8.59 ; \mathrm{p}<0.001$ ) and severe depression (OR $3.17,95 \%$ CI 1.31 to $7.65 ; \mathrm{p}=0.01$ ) were risk factors for hypertension (table 4 ).

\begin{tabular}{|c|c|c|c|}
\hline & $\beta$ & SE & $P$ value \\
\hline \multicolumn{4}{|l|}{ Job burn-out } \\
\hline ERI score & 0.702 & 0.040 & $<0.001$ \\
\hline Male & 0.358 & 0.077 & $<0.001$ \\
\hline Depression & 0.006 & 0.002 & 0.012 \\
\hline \multicolumn{4}{|l|}{ Depression } \\
\hline Job burn-out score & 0.022 & 0.002 & $<0.001$ \\
\hline ERI score & -0.016 & 0.05 & 0.755 \\
\hline Working years & -0.086 & 0.035 & 0.015 \\
\hline
\end{tabular}

All included variables were sex, age, working years, level of education, work type, marital status, working shift, annual income, and ERI score and depression score.

ERI, Effort-Reward Imbalance. 
Table 4 Multivariable logistic regression analysis on influencing factors of hypertension $(n=508)$

\begin{tabular}{|llll}
\hline & OR & $95 \%$ Cl & \begin{tabular}{l} 
value \\
\hline Age
\end{tabular} \\
\hline$\leq 30$ & Ref & \\
\hline $31-45$ & 2.34 & 0.98 to 5.58 & 0.055 \\
\hline$>45$ & 8.39 & 3.53 to 19.95 & $<0.001$ \\
\hline Working types, under ground & 2.09 & 0.95 to 4.57 & 0.065 \\
\hline Working shift & & & \\
\hline Fixed the day & Ref & \\
\hline Work on two shifts & 0.32 & 0.15 to 0.69 & $\mathbf{0 . 0 0 4}$ \\
\hline Three shifts & 1.44 & 0.87 to 2.41 & 0.16 \\
\hline Drinking, yes & 2.55 & 1.30 to 5.00 & $\mathbf{0 . 0 0 6}$ \\
\hline BMI & & & \\
\hline underweighted & 0 & $0.000-$ & 1 \\
\hline Normal & Ref & & \\
\hline Overweight & 0.27 & 0.14 to 0.54 & $<0.001$ \\
\hline Obesity & 1.34 & 0.60 to 2.98 & 0.47 \\
\hline ERI $>1$ & 3.03 & 1.66 to 5.52 & $<0.001$ \\
\hline Depression & & & \\
\hline No & Ref & & \\
\hline Mild & 4.10 & 1.96 to 8.59 & $<0.001$ \\
\hline Moderate & 0.74 & 0.35 to 1.57 & 0.436 \\
\hline Severe & 3.17 & 1.31 to 7.65 & $\mathbf{0 . 0 1}$ \\
\hline P & & & \\
\hline
\end{tabular}

$P<0.05$

BMI, body mass index; ERI, Effort-Reward Imbalance.

\section{DISCUSSION}

In this study, the ERI score was significantly associated with job burn-out and depression score, indicating that occupational stress significantly contributed to job burn-out and depression. In addition, the depression score was associated with job burn-out, suggesting that workers suffering from depression were more likely to experience job burn-out.

The present study strongly suggests that occupational stress is associated with job burn-out, depression symptoms and hypertension in coal miners. The higher the degree of occupational stress, the poorer an individual's mental status and blood pressure. Such relationships were already described in various occupations, but coal miners represent a special group of workers. They work for a long time in the dark, damp underground, under a high degree of danger, which is conducive to suffer from occupational stress. Most available research focused on lung disease, but less on other diseases, especially mental health. Nevertheless, this highlights that the results of the present study have limited generalisability. Indeed, the results might apply only to miners or to individuals working in solitary, isolated locations and under extreme and dangerous conditions. Additional studies will be carried out to validate those results in other types of mining and other countries, especially in the context of a trend toward a lower use of coal as a fuel around the globe.

With economic and social development, work conditions and working procedures have changed dramatically, and workers increasingly experience stress due to complex work environments with high requirements and challenges. These include a high pace of life, fierce competition, complex interpersonal relationships and risk of a variety of diseases. ${ }^{20}{ }^{22}$ Occupational stress is a complex phenomenon resulting from various factors, including molecular biology, occupational health and environmental health. ${ }^{21}$ Occupational stress not only arises from factors including occupational characteristics, interpersonal relationships, human resources, working methods, hazardous substances, and so on, but also involves personal characteristics, family status and culture. This study indicated that coal miners in Xinjiang suffered from occupational stress. The associated factors were working years, educational status, marital status, annual income and sex. The male coal miners involved in this study worked underground in a moist, hot environment; besides, they earned little money to support their families. In China, married individuals with low annual income more easily develop occupational stress since they provide for the whole family, especially coal miners from the countryside. As shown above, participants with a high education level may easily develop occupational stress since they long to engage in creative work, requiring updated technical and working skills.

Burn-out represents a psychological syndrome resulting from a prolonged response to chronic interpersonal stressors at work and manifests as pronounced exhaustion, development of cynical attitudes and feelings, and a sense of ineffectiveness and lack of accomplishment. ${ }^{26}$ This survey found that more than one half of coal miners suffered from job burn-out. Most of the job burn-out were attributed to occupational stress, and job burn-out increased with the ERI score. These results were consistent with a study assessing occupational stress in doctors and nurses. ${ }^{27} \mathrm{Job}$ burn-out is promoted by long-term occupational stress. Sometimes, job burn-out is caused by tedious tasks that may suppress interest in work. Meanwhile, job burn-out results in a negative attitude towards work and indifference to interpersonal relationships. ${ }^{18}$ It is known that tense interpersonal relationships, heavy workload and life pressure contribute to nervous tension. ${ }^{28}$ The multivariable linear regression in this study revealed that occupational stress, sex and depression were associated with job burn-out, which results from prolonged work under pressure. Mental health status is altered by psychological modifications induced by long-term and chronic pressure reactions. ${ }^{29}$ As shown above, males had higher job burn-out levels than females. Depression and burn-out may have similar causes at the biological level. Indeed, Bakusic et al demonstrated that burn-out and depression likely have a common biological basis, that is, 
DNA methylation, which may represent a biomarker of stress-related mental illnesses, including depression and burn-out. ${ }^{30}$ Nevertheless, it should be mentioned that the ERI score had no significant association with depression $(\beta=-0.016, p=0.755)$ in this study.

Mirmohammadi et $a l^{31}$ suggested that occupational stress induces hypertension, hyperlipidaemia and coronary heart disease, in addition to reducing labour efficiency and quality of life. In this study, 508 coal miners underwent health examinations, and the main disease was hypertension, in agreement with previous findings. ${ }^{32}$ These results suggest that the prevention and treatment of cardiovascular diseases should be performed for coal miners. The above associations of hypertension with job burn-out could be explained by that job burn-out is an extreme form of prolonged occupational stress. ${ }^{33}$ Continuous stimulation of the stress state can activate the sympathetic nerve-adrenal medullary axis and release large amounts of catecholamine through the psychology neuroendocrine mechanism, which promotes the secretion of adrenalin and causes the corresponding changes in physiological functions. ${ }^{34}$

Recently, psychological problems in professionals (eg, depression, psychological disorder and anxiety) have sparked concern, with depression representing one of the most common mental health issues and showing a high incidence. ${ }^{33}$ Depression has a negative effect on both society and individuals; more importantly, it causes financial loss and reduces productivity. ${ }^{35}$ This study demonstrated that of the coal miners had severe depression. In addition, the rate of depression in coal miners with occupational stress was higher than that of the occupational stress-free counterparts, corroborating a previous report. ${ }^{36}$ The multivariable linear regression analysis showed that ERI, working years and job burn-out were independently associated with depression. Individuals with high occupationals stress levels more easily developed job burn-out, which is consistent with findings by Shen et al. ${ }^{37}$ Evidence suggests that elevated job burn-out does not only increase the incidence rates of depression and anxiety but also may cause physical diseases. ${ }^{18}$ In this study, coal miners with more than 15 years of employment had tolerated boring and repetitive tasks for a long time; in addition, an adverse working environment (darkness and humidity) negatively affected their mental health. Furthermore, such jobs are defined by constant physical requirements and pressures, which further affect mental health negatively. ${ }^{38}$

The limitations of this survey should be mentioned. First, even though a randomised sampling method was adopted, each cluster should be more specifically assessed. Second, social factors, that is, living environment, social support, organisation and family background were not considered. Third, this study only considered coal diggers, drivers, electrical fitters, haulers, safety workers and ground staff, not including other types of mine workers. In addition, the present study did not compare the occupational levels of coal miners with that of non-miners. Fourth, this cross-sectional study could not reveal the causal associations among occupational stress, job burn-out, depression and hypertension. A cohort study is underway to investigate occupational stresstriggered mental disorders in coal miners of Xinjiang. This will provide additional insights into the importance of eliminating stress and mental health in coal miners.

The present cross-sectional study cannot help determine cause-to-effects among burn-out, depression, job pressure and hypertension. Nevertheless, the present study revealed the deleterious effects of occupational stress on miners. Accordingly, a previous study showed that coal miners in Brazil suffered from anxiety and poor sleep quality. ${ }^{39}$ A study in China indicated that coal miners had depressive symptoms that could be predicted by occupational, psychological factors. ${ }^{40}$ In the USA, the prevalence of obesity and hypertension was reported to be high among coal miners. ${ }^{41}$ The underground environment was identified as being an important cause of hypertension. ${ }^{42}$ The present study expands those previous studies by indicating that a higher degree of occupational stress was associated with poorer mental status and hypertension. It also provides the characteristics of those suffering from occupational stress in the coal miner population. Therefore, available occupational stress counselling and management could ultimately be tailored to this specific population. This calls for the development of national policies on the matter that could improve the quality of life and mental and physical health of coal miners. Nevertheless, the aim of the present study was not to develop such strategies. This will have to be examined in future studies. In this light, the study of the causal relationships among occupational stress, job burn-out, depression and hypertension is necessary.

In conclusion, this survey indicated that $87.2 \%$ of coal miners in Xinjiang suffered from occupational stress. ERI $>1$ was mainly reported by married males with more than 15 years of employment, high education level and annual income below 60000 Yuan. Coal miners with occupational stress had high burn-out and depression scores, indicating that occupational stress promotes job burn-out and depression. Therefore, occupational stress requires interventions via prevention with valid policies and an optimal workplace environment. This would result in an improved quality of life of workers and reduced rates of mental and cardiovascular diseases.

Acknowledgements The authors are grateful to all participants and investigators. Contributors $\mathrm{XY}, \mathrm{XS}$ and $\mathrm{XM}$ carried out the studies, participated in collecting data and drafted the manuscript. JL and XY performed the statistical analysis and participated in its design. XG, ZZ and HG participated in the acquisition, analysis or interpretation of data and drafted the manuscript. All authors read and approved the final manuscript.

Funding The study was supported by the National Natural Science Foundation of China (grant no. 81760581), Graduate innovation and entrepreneurship start-up project of Xinjiang Medical University (no.CXCY2018057) and University research fund project of Xinjiang Province (no.XJEDU2019Y025).

Competing interests None declared.

Patient consent for publication Not required. 
Ethics approval The study was approved by the ethics committee of Xinjiang Medical University.

Provenance and peer review Not commissioned; externally peer reviewed.

Data availability statement All data relevant to the study are included in the article or uploaded as online supplementary information. The datasets used and/or analysed during the current study are available from the corresponding author on reasonable request.

Open access This is an open access article distributed in accordance with the Creative Commons Attribution Non Commercial (CC BY-NC 4.0) license, which permits others to distribute, remix, adapt, build upon this work non-commercially, and license their derivative works on different terms, provided the original work is properly cited, appropriate credit is given, any changes made indicated, and the use is non-commercial. See: http://creativecommons.org/licenses/by-nc/4.0/.

ORCID iD

Xianting Yong http://orcid.org/0000-0003-1949-8980

\section{REFERENCES}

1 Zhang JJ, Jia JM, Tao N, et al. Effect of effort-reward imbalance on job satisfaction of personnel working in sealed cabin of mechanical equipment. J Occup Environ Med 2016;33:998.

2 Yu H-M, Ren X-W, Chen Q, HM Y, Qian C, et al. Quality of life of coal dust workers without pneumoconiosis in mainland China. J Occup Health 2008;50:505-11.

3 Gao XY, Ge H, Jiang Y, et al. Relationship between occupational stress and sleep quality in mental workers. Mod Prev Med 2016;43:3483-7.

4 Magnavita N, Garbarino S, Sleep GS. Sleep, health and wellness at work: a scoping review. Int J Environ Res Public Health 2017;14:1347.

5 Utsugi M, Saijo Y, Yoshioka E, et al. Relationships of occupational stress to insomnia and short sleep in Japanese workers. Sleep 2005;28:728-35

6 Liu F-D, Pan Z-Q, Liu S-L, et al. The estimation of the number of underground coal miners and normalization collective dose at present in China. Radiat Prot Dosimetry 2017;174:302-7.

7 Koutsimani P, Montgomery A, Georganta K. The relationship between burnout, depression, and anxiety: a systematic review and metaanalysis. Front Psychol 2019;10:284-84.

8 Han L, Li Y, Yan W, et al. Quality of life and influencing factors of coal miners in Xuzhou, China. J Thorac Dis 2018;10:835-44.

9 Chu JP, Cai YS, Chang XD, et al. Study on personality traits, mental health and work injury of coal miners. Chin J Health Psychol 2011;19:664-5.

10 WD L. Analysis of the detection of hypertension and hyperglycemia and hyperlipidemia in coal miners of Shouyang 2007-2011. Shanxi J Trad Chin Med 2013;4:876-87.

11 Ran Y. The national development and reform commission approved the construction plan of a large coal base in Xinjiang. Constr mach equip 2015;46:12-16.

$12 \mathrm{Li} \mathrm{H}$, Fan Y, Tian S, et al. Study on the job stress of miners. Procedia Eng 2014;84:239-46.

13 Long V, Brown V. Conceptualizing work-related mental distress in the British coalfields (c.1900-1950). Palgrave Commun 2018;4:133.

14 Meshi EB, Kishinhi SS, Mamuya SH, et al. Thermal exposure and heat illness symptoms among workers in MarA gold mine, Tanzania. Ann Glob Health 2018;84:360-8.

15 Ye K. The survey of the healthy conditions of coal miners in Hechuan area. Chin Med J 2014;12:69-71.

16 Pang Y. Study on the relationship between pressure, general happiness, and psychological health of coal miners. Liao Ning technology university, 2010.

17 Xue WY. Study on the relationship between working pressure and unsafe behavior of underground coal mine workers. An Hui university of science and techonology, 2014.

18 Guan S, Xiaerfuding X, Ning L, et al. Effect of job strain on job burnout, mental fatigue and chronic diseases among civil servants in the Xinjiang Uygur autonomous region of China. Int J Environ Res Public Health 2017;14:872.
19 Li X-yang, Guo Y-song, Zhang Y. [Comment on "the reliability and validity of the effort-reward imbalance - the Chinese version"]. Zhonghua Liu Xing Bing Xue Za Zhi 2006;27:25-8.

20 YX L, Zhang K, Zhao GX. Confirmatory factor analysis of job burnout. Psychol Exploration 2005;25:70-3.

21 Mauno S, Kinnunen U, Ruokolainen M. Job demands and resources as antecedents of work engagement: a longitudinal study. $J$ Vocat Behav 2007;70:149-71.

22 Zhang J, WZ Y, Fang G, et al. Development of the Chinese age norms of CES-D in urban area. Chin Ment Health J 2014;24:139-43.

$23 \mathrm{Li} \mathrm{Y,} \mathrm{Sun} \mathrm{X,} \mathrm{Ge} \mathrm{H,} \mathrm{et} \mathrm{al.} \mathrm{The} \mathrm{status} \mathrm{of} \mathrm{occupational} \mathrm{stress} \mathrm{and} \mathrm{its}$ influence the quality of life of Copper-Nickel miners in Xinjiang, China. Int J Environ Res Public Health 2019;16:353.

24 Liu L-S, Writing Group of 2010 Chinese Guidelines for the Management of Hypertension. [2010 Chinese guidelines for the management of hypertension]. Zhonghua Xin Xue Guan Bing Za Zhi 2011;39:701-38.

25 Chen C, Lu FC, Department of Disease Control Ministry of Health, PR China. The guidelines for prevention and control of overweight and obesity in Chinese adults. Biomed Environ Sci 2004;17 Suppl:1-36.

26 Maslach C, Leiter MP. Understanding the burnout experience: recent research and its implications for psychiatry. World Psychiatry 2016;15:103-11.

27 Liu D. Study on the job burnout situation and its influence factors of clinical nurses in maternal and child health hospital of Hunan Province. Hunan: Zhongnan University, 2013.

28 Embriaco N, Azoulay E, Barrau K, et al. High level of burnout in intensivists: prevalence and associated factors. Am J Respir Crit Care Med 2007;175:686-92.

29 Poncet MC, Toullic P, Papazian L, et al. Burnout syndrome in critical care nursing staff. Am J Respir Crit Care Med 2007;175:698-704.

30 Bakusic J, Schaufeli W, Claes S, et al. Stress, burnout and depression: a systematic review on DNA methylation mechanisms. $J$ Psychosom Res 2017:92:34-44.

31 Mirmohammadi SJ, Taheri M, Mehrparvar AH, et al. Occupational stress and cardiovascular risk factors in high-ranking government officials and office workers. Iran Red Crescent Med J 2014;16:e11747.

32 Wang FL, Qin TB. Study on the relationship between occupational stress and hypertension in coal miners. Zhonghua Lao Dong Wei Sheng Zhi Ye Bing Za Zhi 2013;39:87-93.

33 Salvagioni DAJ, Melanda FN, Mesas AE, et al. Physical, psychological and occupational consequences of job burnout: a systematic review of prospective studies. PLoS One 2017;12:e0185781.

34 Byrne CJ, Khurana S, Kumar A, et al. Inflammatory signaling in hypertension: regulation of adrenal catecholamine biosynthesis. Front Endocrinol 2018;9:343-43.

35 Klemenc-Ketiš Z, Peterlin B. Correlates of depression in the Slovenian working population. Arh Hig Rada Toksikol 2013;64:489-95

36 Phillips MR, Zhang J, Shi Q, et al. Prevalence, treatment, and associated disability of mental disorders in four provinces in China during 2001-05: an epidemiological survey. Lancet 2009;373:2041-53.

37 Shen X, Yang Y-L, Wang Y, et al. The association between occupational stress and depressive symptoms and the mediating role of psychological capital among Chinese university teachers: a cross-sectional study. BMC Psychiatry 2014;14:329-29.

38 Hiesinger K, Tophoven S. Job requirement level, work demands, and health: a prospective study among older workers. Int Arch Occup Environ Health 2019;92:1139-49.

39 Joaquim AC, Lopes M, Stangherlin L, et al. Mental health in underground coal miners. Arch Environ Occup Health 2018;73:334-43.

40 Liu L, Wang L, Chen J. Prevalence and associated factors of depressive symptoms among Chinese underground coal miners. Biomed Res Int 2014;2014:1-9.

41 Casey ML, Fedan KB, Edwards N, et al. Evaluation of high blood pressure and obesity among US coal miners participating in the enhanced coal workers' health surveillance program. J Am Soc Hypertens 2017;11:541-5.

42 Wang M-xiao, Shang Y-xiao. [The relationship between mine environment and hypertension in coal miners]. Zhonghua Nei Ke Za Zhi 2008;47:661-3. 